\title{
An Empirical Analysis of the Dynamic Dependences in the European Corporate Credit Markets: Bonds vs. Credit Derivatives
}

\author{
Sergio Mayordomo ${ }^{\mathrm{a}}$ and Juan Ignacio Peña ${ }^{\mathrm{b}}$
}

This version: February, 2012

\begin{abstract}
In this paper we provide new evidence on the determinants of credit spread returns and their dynamic dependences in three European corporate credit markets: the Bond market (cash market), the Credit Default Swap (CDS) market (derivatives market), and the Asset Swap Package (ASP) market (with properties of both derivatives and cash markets). Using daily data from 2005 to 2009, we find that credit spread returns are primarily driven by innovations and to a lower extent by changes in the expected loss component, the risk premium component, the liquidity premium component and the inertial component whose relative importance changes over time. The intra-market dependence during the current crisis decreases for bonds and ASP innovations but increases slightly for CDS. ASP and bond innovations are closely related, suggesting that the cash component dominates the ASP innovations' behavior. On the other hand CDS's innovations are unrelated with both the bonds' and the ASP's innovations, suggesting that the derivatives element in the ASP contract (due to the implicit interest rate swap) is essentially unrelated with the innovations in the pure credit derivative contract (CDS).
\end{abstract}

Keywords: Credit Spreads, Market Dynamic Dependence, DCC-GARCH.

JEL classification codes: C32, C51, G13, G14.

\footnotetext{
${ }^{\text {a }}$ Corresponding Author: Sergio Mayordomo; Department of Research and Statistics, Spanish Securities Markets Commission, C/ Miguel Ángel 11, 28010 Madrid (Spain); E-mail: smgomez@cnmv.es ; Phone: +34 915850966; Fax: +34 915852278.

${ }^{\mathrm{b}}$ Juan Ignacio Peña is at Universidad Carlos III de Madrid, Department of Business Administration, c/ Madrid 126, 28903 Getafe (Madrid, Spain). E-mail: ypenya@eco.uc3m.es.
} 


\section{Introduction}

The quality of the price signals coming from financial markets is crucial for investment decisions and economic policies. Key to that quality is the understanding of the main determinants of such prices and also the degree of co-movement or dependence of different markets which are trading closely related securities. In this paper we address these two questions related to the relative quality of the price signals coming from three different credit risk markets: the pure cash market (Bonds), the pure derivatives market (CDS) and a market that combine both facets (ASP). ${ }^{1}$ An additional motivation for the research stems from the current discussion on the relative reliability of credit spreads provided by the different markets for credit risk which deserves further empirical testing

The first aim of this paper is to measure the impact of the determinants of credit spreads. According to previous literature, the main determinants of credit spreads are: expected loss, liquidity, tax, risk premium, and macro related factors. Sorting out the determinants of changes in credit spreads is important because the answer to this question has significant implications for policymakers, market participants and academics. For instance, academics should be concerned about the empirical success (or lack thereof) of the structural models of credit risk in explaining changes in corporate credit spreads. The second aim of this paper is to analyze the degree of co-movement or dependence in different credit markets which are trading closely related securities in the context of the subprime crisis. The answer to this question should also interest market participants searching for relative value investment opportunities in bonds, CDS or other credit-related instruments and also should give them relevant information about the proper degree of portfolio diversification.

Our study focuses on daily data for fifty European non-financial firms over the period November 2005 to June 2009. This paper differs from previous literature because it is, as far as we know the first to

\footnotetext{
${ }^{1}$ An ASP contract contains a defaultable coupon bond with a given coupon rate and an interest-rate swap (IRS) that swaps the bond's coupon (fixed leg) into Euribor plus the asset swap spread rate (floating leg). As the asset swap spread valuation is obtained using the bond's face value, an up-front payment must be added to the bond's price at the investment period to ensure that the value of the whole package is the face value.
} 
include the ASP market in the analysis of the changes in corporate credit spreads and because it studies the co-movements or dependencies among three credit risk markets. ${ }^{2}$

The study proceeds as follows. First, we analyze the relative importance of the three main risk factors that the extant literature has identified (expected loss, risk premium, and liquidity premium) in determining credit spread returns. We also include a fourth factor, the inertial factor, to take into account the possible low speed in the price adjustment process due to market frictions. We then analyze the credit spread's dynamic dependence within each market and between markets. To avoid the distorting effect that some factors can have on returns, innovations (i.e. "whitened" returns) are employed. To study the inter-market co-movement or dependence among the three credit markets we estimate the dynamic correlations between the innovations by means of the Dynamic Conditional Correlation (DCC) GARCH model of Engle and Sheppard (2001) and Engle (2002).

The main findings are as follows. First, the proxies for the four factors explain between $11 \%$ and $14 \%$ of the variation in credit spread returns. In the case of the CDS, the larger role is played by the risk premium component whereas for bonds an ASP the largest component by far is the inertial component. Second, the proportion explained by the four components varies over time. Third, intramarket dependence increases slightly during the crisis for CDSs, and noticeably decreases for bonds and ASPs. Fourth, inter-market dependence between bond and ASP innovations are stable and significant in the whole sample period. This fact suggests that the cash component dominates the ASP innovations' behavior in this sample. Inter-market dependence between CDS's innovations and the innovations in the other two markets is negligible. This fact suggests that the innovations are specific to this derivatives market and unrelated to the ones in the other two credit risk markets. To the best of our knowledge, this is the first time that this fact has been documented. Therefore, Bonds and ASP

\footnotetext{
${ }^{2}$ The analysis of the ASP spreads is of special interest because this market has been considered as a source of more accurate measures of credit risk, under some circumstances, than bond spreads by some authors as Francis et al.(2003), and Mayordomo et al. (2011), among others. ASP are widely used as a reference for credit derivative pricing and are a key tool to convert long-term fixed-rate assets, to floating rate assets to match the short term liabilities. The British Bankers Association 2002 survey estimated that the size of the asset swap market was around $12 \%$ of the total credit derivatives markets representing an outstanding notional of around $\$ 100$ billion by year 2000. However, the percentages reflecting the ASP market size are believed to be a lower limit given that many institutions do not formally classify ASP as credit derivatives given its cash facet.
} 
innovations seem to be closely related whereas CDS innovations have a clearly differentiated behavior.

The remainder of the paper is organized as follows: Section 2 discussed related literature. Section 3 outlines the methodology. Section 4 describes the data set while Section 5 presents and discusses the results. Section 6 concludes.

\section{Related Literature}

The first generation of studies on corporate credit spreads determinants was focused on the bond (cash) market. Elton, Gruber, and Agrawal (2001) obtain that the expected default accounts for a small fraction of the spreads in corporate rates, taxes explain a substantial portion and the remaining portion is closely related to factors explaining risk premiums for common stocks. In the same line, CollinDufresne, Goldstein and Martin (2001) analyze credit spread changes and find that the innovations are mostly driven by a single common systematic factor which could be due to the supply/demand shocks or to an aggregate factor driving liquidity in the bond market. Perraudin and Taylor (2003) decompose the defaultable bond spreads into different components such as expected losses, taxes, risk premiums and an additional factor, liquidity premium, to focus directly on the impact of liquidity on bond spreads. Their results show that liquidity premiums are as large or larger than risk premiums and much larger than expected losses. Delianedis and Geske (2002) conclude that the credit risk and credit spreads are not primarily explained by default and recoveries, but are mainly attributable to taxes, jumps, and liquidity and market factors. Chen, Lesmond and Wei (2007) analyze the influence of liquidity on bond spreads and obtain that it explains up to half of the cross-sectional variation in spread levels and up to two times the cross-sectional variation in spread changes that is explained by the effects of credit rating alone.

Other group of researchers has focused in analyzing the determinants and components of the credit spread for the CDS market. Longstaff, Mithal and Neis (2005) estimate the CDS's default component from both a model-free approach and a structural approach to analyze the determinants of the nondefault component from liquidity and macroeconomic measures. They find that the default component 
accounts for the majority of the corporate spread across all credit ratings and the non-defaultable component is strongly related to bond illiquidity. Ericsson, Jacobs and Oviedo-Helfenberger (2009), on the contrary to Collin-Dufresne et al (2001), find weak evidence of a single strong latent common factor. Tang and Yan (2007) show that both liquidity level and liquidity risk are significant factors in determining CDS spreads and both together could account for around 20\% of CDS spreads. Using a sample of European banks, Annaert, De Ceuster, Van Roy and Vespro (2010) find that individual CDS liquidity and market wide liquidity premia played a dominant role in the steeply rising CDS spreads in the recent financial crisis. We share some of the objectives pursued by these previous papers. However, this paper is the first that analyzes empirically the determinants of the asset swap spreads. The set of determinants employed in our analysis enables us to infer some conclusions about the reliability of structural models and about the potential existence of inefficiencies in the credit markets.

We define intra-market and inter-market dependence in terms of the correlation structures between two credit spread innovations obtained after subtracting the effect of the changes in the expected loss component, which is proxied by company-level variables and instantaneous risk-free rates on the spirit of the Merton (1974) model, and also the effect of changes in the risk and liquidity premiums from the credit spreads. To capture the characteristics of time-varying correlations we employ the Dynamic Conditional Correlation (DCC-GARCH) model of Engle (2002), which is particularly well-suited to examining correlation dynamics among assets. The higher the innovation's correlation, the stronger the market co-movement is. We test both the intra-market co-movements (within a given market) and the inter-market co-movements (between two given markets). Our measure of intra-market dependence is based on the correlation between an individual firm i's (firm-specific) credit spread innovation, and the corresponding average (market-specific) credit spread innovations which are obtained as an equally weighted average of the innovations of all the firms with the exception of firm i's innovations. Similarly, our measure of inter-market dependence is based on the DCCs between the two individual credit spread innovations of the same firm (firm-specific) but in different markets. The DCC models have been employed to study the co-movement among different financial markets and among different 
economic areas as in Kim, Lucey and Wu (2005), Cappiello, Engle and Sheppard (2006), Li and Zou (2008), or Savva, Osborn and Gill (2009) among others.

In related research, Acharya, Schaefer and Zhang (2007) analyze the existence of correlation risk in credit markets in the context of the Ford and GM downgrades in May 2005 and find excess comovement in the overall fixed-income securities. Coudert and Gex (2008) study the variations in the correlation between CDS premium around the episode of Ford and GM downgrades by using different measures such as the DCC-GARCH model. They find a significant increase in CDS premium correlations between firms during the previous episode. Alexopoulou, Andersson, and Georgescu (2009) study the movements between European corporate bonds and CDS spreads by comparing the sensitivity of the credit spreads to systematic, idiosyncratic risk factors and liquidity in the context of the subprime crisis. They find that after the summer 2007 the CDS market becomes more sensitive to systematic risk while the bond market depends on a higher extent on liquidity and idiosyncratic risk. Additionally, Anderson (2010) documents an increase in the correlation of CDS spreads during the credit crisis and finds that changes in the risk premium completely explains the increase in excess correlation in the CDS market and so, the risk premium was the main channel for contagion. However, none of the previous papers include the ASP market in their analysis of credit markets interdependences. Our paper fills this gap in the literature. Our approach differs from the previous ones given that we study the behavior of the filtered or unexplained credit spread returns on the basis of a DCC-GARCH model.

\section{Methodology}

This section is divided in three subsections. First, we show how to break down the credit spread into four components related to expected loss, risk premium, liquidity premium and inertial component respectively, extending Boss and Scheicher (2002) and Amato (2005) framework. Second, we introduce a regression model where the explanatory variables are chosen to be the main drivers for each component. The choice of the explanatory variables is motivated by theoretical arguments as well as by previously published empirical studies. Third, we discuss how to use the regression's 
innovations to study the dynamic dependence both intra-market and inter-markets by means of a DCC GARCH.

\subsection{Credit Spread Components}

In the framework of the structural credit risk models in the Merton's (1974) tradition, it is assumed that the credit spread level, $S(t)$, is determined through the current values of the relevant state variables (firm value and interest rates among them). Then, credit spread changes, $S(t)-S(t-1)$, or returns, $\ln (S(t) / S(t-1))$ are determined by changes or returns respectively in these state variables. Previous literature analyzed levels (Perraudin and Taylor (2003) or Tang and Yan (2007 among others), changes (Collin-Dufresne, Goldstein and Martin (2001), Annaert, De Ceuster, Van Roy and Vespro, (2010); Anderson (2010); Alexopolou, Andersson and Georgescu, (2009) among others), or levels and changes (Chen, Lesmond and Wei (2007); Ericsson, Jacobs and Oviedo-Helfenberger, (2009) among others). Other analyses as Delianedis and Geske (2002) or Longstaff, Mithal and Neis (2005) analyze the difference between the observed credit spreads and model based credit spreads. However, our variable of interest is defined as the credit spread returns. The use of the credit spread returns is motivated by the model that we use to break down the credit spreads into their main determinants. The use of credit spreads in levels, when these credit spreads are integrated of order one as it is often the case, raises controversial questions on how to deal with the possible cointegration relations (among credit spreads and the explanatory variables) that should be included in the regression model. The use of credit spread changes could also introduce complications in the subsequent analysis because according to our theoretical framework, the factors which determine credit spreads are not additive.

Our theoretical framework supporting the empirical analysis is an extension of Boss and Scheicher (2002) and Amato (2005). The credit spread $S$ at time $t$ for asset $j$ (j=1(CDS), 2(ASP), 3(Bond)) and firm $i$ can be broken down into four components (abstracting from transaction fees and tax effects): the expected loss $(e l)$, the risk premium $(p d r=(1+p r)$ where $p r$ is the price of default risk), the liquidity premium $(p d l=(l+p l)$ where $p l$ is the price of liquidity risk) and the inertial component $(i c)$ as follows:

$$
S(j, i, t) \approx e l(j, i, t) * p d r(j, i, t) * p d l(j, i, t) * i c(j, i, t)
$$


or equivalently:

$$
S(j, i, t) \approx e l(j, i, t) *(1+p r(j, i, t)) *(1+p l(j, i, t)) * i c(j, i, t)(2)
$$

The expected loss is defined as $e l(j, i, t)=d p(j, i, t) * \lg d(j, i, t)$ where $d p(j, i, t)$ is the (real world) default probability and $\lg d(j, i, t)$ is the loss given default.

The price of default risk $\operatorname{pr}(j, i, t)$ has the interpretation of the compensation per unit of expected loss paid to investors to bear exposure to default risk. Similarly, the price of liquidity risk $p l(j, i, t)$ has the interpretation of the compensation per unit of expected loss paid to investors to bear exposure to liquidity risk. Both prices are indicators of investor's aversion to default and liquidity risk, respectively. The inertial component contains lagged credit spreads as well as lagged explanatory variables. To linearize (2) we take logs such that:

$$
\ln (S(j, i, t)) \approx \ln (e l(j, i, t))+\ln (1+\operatorname{pr}(j, i, t))+\ln (1+p l(j, i, t))+\ln (i c(j, i, t))(3)
$$

and compute the credit spread returns (CS) for the credit instrument $j$ and firm $i$ at time $t$ as $C S(j, i, t)=\ln (S(j, i, t))-\ln (S(j, i, t-1))$. The expected loss returns are denoted as $\operatorname{cel}(j, i, t)=\ln (e l(j, i, t))-$ $\ln (e l(j, i, t-1))$, the risk premium returns as $\operatorname{cpr}(j, i, t)=\ln [1+\operatorname{pr}(j, i, t)]-\ln [1+\operatorname{pr}(j, i, t-1)]$, the liquidity premium returns as $\operatorname{cpl}(j, i, t)=\ln [1+p l(j, i, t)]-\ln [1+p l(j, i, t-1)]$. and the inertial returns as $\operatorname{cic}(j, i, t)=$ $\ln (i c(j, i, t))-\ln (i c(j, i, t-1))$. The credit spread returns can be presented in terms of the expected loss, risk premium, and liquidity premium:

$$
C S(j, i, t) \approx \operatorname{cel}(j, i, t)+\operatorname{cpr}(j, i, t)+\operatorname{cpl}(j, i, t)+\operatorname{cic}(j, i, t)
$$

Therefore, the return in credit spreads is linearly related to the return in expected losses, the return in the risk premium, the return in the liquidity premium, and the return in the inertial component. In the next section we address the empirical modeling of the four components by means of a regression model. Our decomposition allows for a specific factor including the inertial component to take into account the possible market frictions in the price adjustment process. This is important because in many previous studies the effect of the lagged credit changes is arbitrarily included into one of the 
other three components (usually in the expected loss term) overweighting their relevance and exaggerating the explanatory power of the variables based on structural credit risk models. ${ }^{3}$

\subsection{Regression Model}

In this section we describe the regression model we employ to isolate each component as defined above. We first estimate the change in the expected loss component, cel(j,i,t), using a non-linear Merton(1974)-based component, following Acharya, Schaefer, and Zhang (2007) and Acharya and Johnson (2007). Next we enumerate the company-level variables employed as the drivers for this component. We use the contemporaneous firm stock return to capture the firms' financial health, the product of that return and the inverse CDS level, and the squared of the individual firm's stock returns as a proxy for the individual stock volatility. Additionally, we also include the changes in the logarithm of the instantaneous risk-free rate (EONIA).

The drivers of second component, the change in the risk premium component $c p r(j, i, t)$, are market factors: market's return, market's volatility (squared of market's returns), and the implied volatility VDAX index. In order to control for an additional source of risk which cannot be diversified away we also use a systemic risk proxy (LIBOR-OIS). ${ }^{4} \mathrm{We}$ also include as additional drivers of this component some interest rates-related variables as suggested in Longstaff and Schwartz (1995), Boss and Scheicher (2002) and Collin-Dufresne, Goldstein and Martin (2001). Specifically, we include the 10year Interest Rate Swap (IRS) returns, the historical volatility of such returns, and the percentage changes in the term structure slope which is defined as the 10-year minus the 3-month IRS rates. The historical volatility of the interest rates is estimated by means of the historical volatility on the basis of

\footnotetext{
${ }^{3}$ There is an argument on the extent to which the counterparty risk may play a role in the pricing of CDS contracts, see Stulz (2009) and Arora et al. (2009) and therefore an additional component might be included in the CDS spread to take into the account this factor. A recent European Central Bank report, ECB (2009), stresses the growing importance of the counterparty risk in the European CDS market, especially after the Lehman bankruptcy. We posit a proxy to analyze the effects of such a risk. This proxy is constructed by means of the first principal component obtained from the CDS spreads of the main banks which act as dealers in this market and is employed as a robustness test in the corresponding section.

${ }^{4}$ The systemic risk proxy is defined as the difference between the Euro Interbank Rate (BBA LIBOR) minus Euro Interest Rate Swaps (Overnight Swap). This measure has been found to be one of the best measures of systemic risk in the European banking system by Rodriguez-Moreno and Peña (2010).
} 
a GARCH $(1,1)$ model. First of all, we compute the logarithm of the ratio formed by the interest rates at time $\mathrm{t}$ divided by the rates one day ago. Then we fit a GARCH process to these data.

The drivers of the third component, the change in the liquidity premium $c p l(j, i, t)$, are changes in idiosyncratic (CDS and bond bid-ask spreads) and market-wide liquidity measures. Global liquidity is proxied by means of the difference between the 90-days US AA-rated commercial paper interest rates for the financial companies and the 90-days US T-bill. This is a dimension of liquidity related to overall funding constraints as suggested in Acharya, et al. (2007). ${ }^{5}$

Finally, and to take into account the market's frictions and possible lags in the price's adjustment process we include an inertial component $\operatorname{cic}(j, i, t)$, including lagged values of credit spreads changes and stock returns, as well as the product of the lagged stock returns and the inverse of the contemporaneous CDS level.

In summary, the regression model breaks down the credit spread returns into four terms. The first one refers to the extended Merton-model component reflecting changes in the expected loss while the other two components reflect changes in the risk premium and liquidity factors. The last one is the inertial component. The equation we formally estimate is as follows:

\footnotetext{
${ }^{5}$ These variables as well as the risk premium variables are proxied on the basis of the U.S. financial sector. Although we are using European firms, we use variables based on U.S. information to reflect a global investor's behavior.
} 


$$
\begin{aligned}
C S(j, i, t)=\alpha & +\sum_{k=1}^{5} \beta_{k} \operatorname{CS}(j, i, t-k)+\sum_{k=0}^{5} \gamma_{k} \operatorname{Stock} \operatorname{Return}(i, t-k) \\
& +\sum_{k=0}^{5} \delta_{k}[\operatorname{Stock} \operatorname{Return}(i, t-k) / S(j, i, t)]+\zeta(\operatorname{Stock} \operatorname{Return}(i, t-k))^{2} \\
& +\omega \ln \left[\frac{r(t)}{r(t-1)}\right]+\eta \ln \left[\frac{r 10 y(t)}{r 10 y(t-1)}\right]+\theta \operatorname{StdDev}\left[\ln \left(\frac{r 10 y(t)}{r 10 Y(t-1)}\right)\right] \\
& +\vartheta \ln \left[\frac{\operatorname{Slope} 10 y-3 m(t)}{\operatorname{Slope} 10 y-3 m(t-1)}\right]+\kappa \ln \left[\frac{V D A X(t)}{\operatorname{VDAX}(t-1)}\right]+\lambda S \& P 500 \operatorname{Return}(t) \\
& +\iota(\operatorname{S\& P} 500 \operatorname{Return}(t))^{2}+v \ln \left[\frac{\operatorname{LIBOR}-O \operatorname{OIS}(t)}{\operatorname{LIBOR}-O I S(t-1)}\right]+\varsigma \ln \left[\frac{\operatorname{CDSLiq}(t)}{\operatorname{CDSLiq}(t-1)}\right] \\
& +\pi \ln \left[\frac{\operatorname{BondLiq}(t)}{\operatorname{BondLiq}(t-1)}\right]+\varpi \ln \left[\frac{\operatorname{GlobalLiq}(t)}{\operatorname{GlobalLiq}(t-1)}\right]+\varepsilon(j, i, t) \quad \text { for } j \\
& =1(\operatorname{CDS}), 2(\operatorname{ASP}), 3(\text { Bond }) \text { and } i=1, \ldots, 50
\end{aligned}
$$

where $C S(1, i, t), C S(2, i, t)$ and $C S(3, i, t)$ represent the corresponding CDS, ASP and Bond spread returns, respectively, and $S(1, i, t), S(2, i, t)$ and $S(3, i, t)$ represent the CDS, ASP and Bond spreads of firm i at time t, respectively. The firm stock returns are denoted as Stock Return $(i, t)$ and are obtained as $\ln [$ Stock Price $(i, t-k) / S t o c k$ Price $(i, t-k-1)]$. The non-linear term is represented by the ratio of the stock returns and the credit spreads: Stock Return $(i, t-k) / S(j, i, t)$. We denote as $r$ and rloy the instantaneous risk-free (EONIA) and 10-year IRS rates, respectively, while the changes in the 10-year IRS rate volatility are denoted as $\operatorname{StdDev}[\ln (r 10 y(t) / r 10 y(t-1))]$. Slope10y-3m is the difference between the 10-year and 3-month IRS rate. The returns in the VDAX Index are represented as $\ln (\operatorname{VDAX}(t) / \operatorname{VDAX}(t-1))$. The $\mathrm{S} \& \mathrm{P} 500$ Index returns are denoted as $S \& P 500$ Return $(t)$ and are obtained as $\ln [S \& P 500 \operatorname{Index}(t) / S \& P 500$ Index(t-1)]. The remaining variables are the log returns of the systemic-risk measure $(\operatorname{LIBOR}-O I S(t))$, and the CDS, bond and global liquidity measures (CDSLiq(i,t), BondLiq(i,t), and GlobalLiq(i,t), respectively). The innovations for the CDS, ASP and Bond spread returns are denoted as $\varepsilon(1, i, t), \varepsilon(2, i, t)$, and $\varepsilon(3, i, t)$, respectively.

Regarding the estimation method, we fit an unbalanced panel model using Ordinary Least Squares (OLS) regression robust to heteroskedasticity and cross-sectional correlation across firms for each 
market (CDS, ASP, and Bond markets). We run a Hausman test and find no significance evidence for the existence of fixed-effects. Additionally, and in order to extract the individual credit spreads innovations we estimate the previous equation firm by firm by means of an OLS regression robust to heteroskedasticity.

\subsubsection{Expected Signs}

a) The Expected Loss Component:

- Individual Stock returns: According to their role in the Merton model, a drop in stock prices increases leverage and generate uncertainty about a firm's debt repayment capacity. It should be reflected in a higher default probability and as a consequence in higher credit spreads. The expected sign is negative.

- Interaction between stock returns and credit spreads: In this ratio the numerator (stock returns) has an expected negative sign, as discussed above and the denominator has also an expected negative sign. The non-linear combination of both effects makes the overall expected sign unclear.

- Individual Stock volatility: The Merton (1974) approach implies that the credit-related claims have features similar to a short position in a put option. Since option values increase with volatility, it follows that this approach predicts credit spreads should increase with volatility. Therefore, increased volatility increases the probability of default. Thus, we expect a positive sign.

- $\quad$ Changes in the instantaneous risk-free rate (EONIA): Standard models of risky debt (e.g. Longstaff and Schwartz (1995)) imply that an increase in the spot rate increases company's value because the higher reinvestment rate increases firm's future value, decreasing its default probability. So, an increase in the spot rate leads to tighter spreads. Therefore the expected sign is negative.

b) The Risk Premium Component:

- $\quad$ S\&P 500 returns: the expected sign for this variable is negative for the same argument employed in the case of the firm's stock returns and because it gives useful information on expectations about changes in business climate.

- $\quad$ Squared S\&P 500 returns (volatility): This can be thought as a measure of the degree of economy-wide uncertainty and therefore its expected sign is positive. 
- Changes in VDAX Index: This variable is a forward looking measure of the overall macroeconomic uncertainty and so, we expect a positive sign. ${ }^{6}$

- $\quad$ Changes in the 10-year Interest Rate Swap (IRS) rate: Long-term IRS rates can be viewed as a reasonable proxy for the overall macroeconomic outlook. If the sign turns out to be positive this is consistent with the financing costs arguments (higher financing costs imply higher default probabilities). If it is negative this is consistent with the Fisher hypothesis which states that the yield offered on a risk-free bond can be broken down into a real rate component and an expected inflation component. Given that the real rate component is positively related to the economic growth prospects, increases in long run rates would imply lower default probabilities. Then the expected sign is unclear and must be determined empirically.

- $\quad$ Changes in the 10-year IRS rate volatility: A less stable macro environment, as measured by the volatility of the changes in the interest rates, will increase credit spreads and therefore we expect a positive sign.

- $\quad$ Changes in the Slope $(10 \mathrm{y}-3 \mathrm{~m})$ : A higher value for this variable will indicate a steep yield curve. Positively sloped yield curves are usually leading indicators of good economic growth prospects implying lower default probabilities and therefore, we expect a negative sign.

- $\quad$ Changes in the Systemic risk factor: We expect that increases in systemic risk also increase default probabilities and therefore the expected sign is positive.

c) The Liquidity Premium Component:

- $\quad$ Changes in Bond liquidity (bid-ask spread): We expect a positive sign in this variable, when the dependent variables are the bond or the asset swap spreads changes, because when liquidity dries up bid-ask spreads widen, liquidity risk increases and traders are willing to pay a higher price for avoiding this risk. In the CDS case the sign is unclear. On the one hand, the illiquidity in the bond market could decrease the demand of hedging instruments (positive expected sign). On the other hand,

\footnotetext{
${ }^{6}$ We use the VDAX Index instead of the VIX Index to avoid collinearity problems due to the high correlation between the VIX Index and S\&P 500 returns.
} 
the investor could decide to invest in CDS contracts if it is easier to take positions in these contracts (negative expected sign). ${ }^{7}$

- $\quad$ Changes in CDS liquidity (bid-ask spread). As it is the case with the bond spreads, the CDS spread has a liquidity premium such that the lower the CDS liquidity, the higher is the CDS spread. For this reason, we expect a positive sign in this variable when the dependent variable is the CDS spread change. In the case of ASP and Bonds, the sign is unclear for similar reasons as the ones discussed in the previous point.

- $\quad$ Changes in Global Liquidity: the wider the spread the tighter the liquidity conditions and therefore we expect a positive sign in this variable.

d) The Inertial Component: This component includes lagged effects of several explanatory variables to control for potential market frictions associated to the delayed response to information. As in Acharya and Johnson (2007) we allow for five lags of each of the following variables:

- $\quad$ Lagged credit spreads: The lags of the credit spread allow quantifying the speed of adjustment. If there is mean reversion in the credit spreads we should expect a negative sign. The higher the coefficient, the stronger is the mean reversion.

- $\quad$ Lagged individual stock returns: Lagged values are also included because it has been reported (see Kwan (1996)) that lagged equity returns have an impact on changes in credit spreads. We expect a negative sign mirroring the contemporaneous effect of the individual stock returns.

- Interaction between stock returns and credit spreads. The expected sign of this non-linear combination is unclear.

The sample is formed by investment-grade firms. It is worth noting that investment-grade corporate bonds very rarely default. Elton, Gruber, and Agrawal (2001) argue on this basis that expected default can account for only a small part of the yield spread for investment-grade corporate over the risk free rate, while state taxes, which are payable on corporate interest but not on Treasury interest, are relatively much more important. In Europe the tax effect is not relevant (income from corporate and

\footnotetext{
${ }^{7}$ Although we do not have any illiquidity measure for the ASPs, we proxy it by means of the bid-ask spread of the underlying bond in the ASP. The ASP consists of a corporate bond and an IRS, but the IRS is a very liquid instrument and thus, we focus on the importance of the bond illiquidity measure.
} 
government bonds attracts the same rate for European residents) and thus we have the advantage that a potential confounding factor, namely the tax differences between securities, is absent.

\subsection{Estimation of the Dynamic Conditional Correlations}

We use the innovations from equation (5) to analyze market dependence or co-movements. A given pair of these innovations $\varepsilon_{i, t}=\left(\varepsilon_{1, i, t}, \varepsilon_{2, i, t}\right)^{\prime}$ is assumed to follow a Normal distribution such that $\varepsilon_{i, t} \mid I_{i, t} \sim N\left(0, H_{t}\right)$.

In order to study the inter-market co-movement or dependence between the CDS and ASP markets (we use this pair of credit markets to illustrate the methodology), or any other pair of markets, we obtain the dynamic correlations between the innovations by means of the DCC-GARCH model (Dynamic Conditional Correlation GARCH) of Engle and Sheppard (2001) and Engle (2002). This methodology allows us to analyze the evolution over time of the second moments and to detect any regime shifts or responses to shocks and also to distinguish the different behavior of shocks before and during crisis periods.

Company by company, we estimate the residuals $\varepsilon_{1, i, t}$ and $\varepsilon_{2, i, t}$ and form pairs by firm i in order to estimate bivariate DCC-GARCH models and the series of DCCs between ASPs and CDSs. ${ }^{8}$ The multivariate conditional covariance matrix can be written as:

$$
H_{t}=D_{t}^{1 / 2} V_{t} D_{t}^{1 / 2}
$$

where $D_{t}$ is a $2 \times 2$ diagonal matrix formed by conditional variances from univariate GARCH models with $h_{i i, t}$ on the ith diagonal, and $V_{t}$ is a matrix that contains the conditional correlations of the pairwise residuals. The variance-covariance matrices are expanded into individual equations as:

$$
\begin{gathered}
h_{i i, t}=c_{i}+a_{i} h_{i i, t-1}+b_{i} \varepsilon_{i, t-1}^{2}, \quad i=1,2 \\
h_{i j, t}=\rho_{i j, t} \sqrt{h_{i i, t}} \sqrt{h_{j j, t}}, \quad i, j=1,2 \text { and } i \neq j
\end{gathered}
$$

\footnotetext{
${ }^{8}$ In total, we have 50 series of DCCs given that in some cases we have several ASPs by firm.
} 
where $h_{i i, t}$ and $h_{j j, t}$ are, respectively, the conditional variance and conditional covariance with $i, j=$ 1,2 and $i \neq j$. The conditional correlation coefficient $\rho_{i j, t}$ is obtained as:

$$
\rho_{i j, t}=\frac{q_{i j, t}}{\sqrt{q_{i i, t} q_{j j, t}}}, \quad i, j=1,2 \text { and } i \neq j
$$

where the conditional covariance $q_{i j, t}$ between the standardized residuals $\eta_{i, t}=\frac{\varepsilon_{i, t}}{\sqrt{h_{i i, t}}}$ and $\eta_{j, t}=\frac{\varepsilon_{j, t}}{\sqrt{h_{j j, t}}}$ can be expressed in a mean reverting process given by:

$$
q_{i j, t}=\overline{\rho_{l \jmath}}(1-\alpha-\beta)+\alpha \eta_{i, t-1} \eta_{j, t-1}+\beta q_{i j, t-1} i, j=1,2 \text { and } i \neq j
$$

with $\alpha+\beta<1$ and $\alpha, \beta>0$ and $\overline{\rho_{l j}}$ is the unconditional correlation between $\varepsilon_{1, i, t}$ and $\varepsilon_{2, i, t}$. The mean of $q_{i j, t}$ is $\overline{\rho_{l \jmath}}$ and the variance is unity.

Engle and Sheppard (2001) and Engle (2002) state that the DCC model was designed to allow for twostage estimation, where in the first stage univariate GARCH models are estimated for each innovations series and, in the second stage, the standardized innovations are used to estimate the parameters of the dynamic correlation model.

We repeat the same procedure for the CDS and Bond (ASP and Bond) markets and form pairs to estimate the DCCs between the CDS and Bond innovations (ASP and Bond innovations) for each firm. Inter-market dependence is studied using, for instance, CDS innovations for a given name $i$ and ASP or bond innovations for the same name $i$ to form pairs of residuals and then, we estimate a bivariate DCC-GARCH model for each pair.

In order to study the intra-market dependence, for instance using the CDS market, we employ the CDS innovations for a given name $i$ and the average innovations of the rest of the names, excluding name $i$, to form pairs of residuals and then, we estimate a bivariate DCC-GARCH model for each pair. In terms of the above framework we compute the correlation between a series of firm $i$ innovation $\varepsilon(j, i, t)$ and another series of market innovations $\varepsilon(j, m, t)$ where $m$ means market average. We use the same procedure to estimate DCCs with ASP innovations and also with Bond innovations. 
When the credit spread innovations are highly correlated, they will tend to move together on the up side or on the down side. Conversely, when the innovations are lowly correlated, they will often diverge. The higher the correlation, the larger the credit spread innovations co-movement within or between markets and the greater the market dependence. As the financial crisis has had a significant impact on the credit markets, we wish to establish whether the correlations between them have changed over the sample period, suggesting increasing or decreasing financial co-movements.

\section{Data}

Our database contains daily data on Eurobonds and ASPs denominated in Euros and issued by nonfinancial companies that are collected from Reuters, and on CDSs also denominated in Euros, whose underlying firms are the same non-financial companies, that are obtained from GFI. GFI is a major inter-dealer broker (IDB) specializing in the trading of credit derivatives. GFI data contain singlename CDS market prices for 1, 2, 3, 4 and 5 years maturities. These prices correspond to actual trades, or firm bids and offers where capital is actually committed, and so they are not consensus or indications. For some companies and for some maturities, especially two and four years, the data availability is scarce and in these cases we employ mid-price quotes from a credit curve also reported by GFI to fill the missing data.

For each bond there is information on both bid and ask prices, the swap spread, the asset swap spread, the sector of the entity and its geographical location, the currency, the seniority, the rating history (Fitch, S\&P and Moody's ratings), the issuance date and the amount issued, the coupon and coupon dates, and the maturity. Our sample contains fixed-rate senior unsecured Euro denominated bonds whose issued quantity exceeds 300 million Euros to avoid the selection of bonds with small volume and reduced liquidity. Credit spreads are defined as the difference between the yield of a given bond and its associated swap rate at the same maturity. We use bonds whose maturity is lower than five years at the first date in which an observation is included in the sample. Bonds with time to maturity equal to or less than twelve months in the date corresponding to their last observation are excluded. Several bonds issued by the same company may be used whenever they satisfy all the required criteria. 
Bond maturity decreases along time while the CDS spreads refer to a 5-year constant maturity. Thus, as the bond's maturity date approaches, the use of CDSs with a 5-year constant maturity to be compared against the bonds makes the CDS spreads to be higher than the bond spreads by definition. Related studies overcome this problem by considering constant-maturity bond spreads calculated from synthetically generated corporate bond yields (e.g., Blanco, Brennan and Marsh (2005), Zhu (2006), and Norden and Weber (2009)). We take advantage of the range of CDSs maturities to fit a CDS curve using a Piecewise Cubic Hermite Interpolating Polynomial (PCHIP) algorithm that permits us to match ASP and CDS maturities. This method is also used in Levin, Perli, and Zakrajsek (2005).

Daily data on individual stock prices, stock indexes, implied volatility indexes, as well as the swap rates, interbank rates, and overnight rates are obtained from Reuters. Daily data on the commercial paper and T-bill interest rates are obtained from Datastream. The data spans from November 1st, 2005 to June 29th, 2009. The sample consists of 38 non-financial companies and 50 ASPs and bonds. ${ }^{9}$ Our sample size is comparable to others in the literature on CDS and bond spreads, both in terms of sample size and number of companies. ${ }^{10}$

Table 1 reports descriptive statistics on asset swap, bond and CDS spreads. Table 1 provides descriptive statistics for the entire sample of 150 instruments (CDS, ASP and Bonds), totaling 34,640 observations for each group of instruments. Table 1 shows that the average credit spreads do not differ substantially among the instruments, being the average bond spread the highest (55.37 b.p.) and the average ASP credit spread the lowest (53.90 b.p.). The volatility is highest for CDS spreads (54.37 b.p.) and lowest for ASP spreads (49.69 b.p.).

\footnotetext{
${ }^{9}$ Our initial sample was 285 corporate bond issuers. We found a total of 116 Euro denominated bonds that mature before February 2012 but only 67 of them include enough information on 5-year bid/ask CDS spreads, asset swap spreads and Fenics Curve. Of these, two bonds have been discarded because the issued amount does not exceed 300 million Euros, and another four bonds were discarded because they were not investment grade bonds throughout the whole sample period. Another four bonds were discarded because their asset swap spreads were persistently negative and, finally, seven bonds were discarded because prices were too far from par. Thus, although we consider all the bonds issued by non-financial European companies to be employed in our study, the...final number of bonds is 50 due to the imposed requirements.

${ }^{10}$ Longstaff, Mithal, and Neis (2005) include 68 firms from March 2001 to October 2002, Blanco, Brennan, and Marsh (2005) use 33 American and European companies from January 2001 to June 2002, Zhu (2006) uses 24 investment grade companies from January 1999 to December 2002, and Forte and Peña (2009) employ data for 20 companies from September 2001 to June 2003.
} 


\section{Results}

\subsection{The Determinants of Credit Spreads}

Table 2 reports the results for the panel specification in equation (5). Regarding the variables proxying for the expected loss factor, we find that, in agreement with the theory, contemporaneous stock returns have a negative and significant impact on the CDS spread returns. However, they do not have a significant impact on ASP and bond spreads returns. The interaction between the stock returns and the credit spreads has a positive and significant effect for CDS and ASP but it is not significant for Bonds. We should expect a positive sign for the firm's volatility in accordance with Merton's model because rising firm's stock returns variability means more uncertainty about future asset values and therefore higher default probabilities. And indeed, we find a positive a significant effect of this variable in the case of CDS but this effect is not significant for ASP and for Bonds. The effect of the EONIA variable is, as expected, negative but it is only significant for CDS. Summarizing the results for this first set of variables, we find that all variables in this section help to explain changes in CDS spreads, the ratio of the stock returns to credit spreads has some explanatory power for the ASP spreads but none of the expected loss proxies have any significant explanatory power in the case of Bonds.

Turning to the effects of the risk premium proxies, all of them have usually the expected sign. Changes in the VDAX index have strong positive effect on CDS as expected. However this variable is not significant for ASP and Bonds. S\&P500 returns have the expected negative and significant effect on CDS and Bonds. S\&P500 squared returns have a positive and significant effect on the three markets as expected. The proxy for the systemic risk factor, the difference between Libor and the Overnight Interest Rate Swap has the expected positive effect on the three markets but is, somewhat surprisingly, not significant for CDS.

With respect to the impact of the three interest-rate related variables, and consistent with the empirical findings of Longstaff and Schwartz (1995) and Collin-Dufresne et al. (2001), we find that an increase in the 10-year interest rate lowers the credit spread in all cases but its effect is not significant for Bonds. The implication is that increments in long-term interest rates may signal favorable perspectives 
about future macroeconomic climate which should lower the default risk for firms. The changes in the volatility of the 10-year interest rate have a positive effect in all cases but are only significant in the case of ASP. Given that the influence of the changes in the volatility of interest rates on spread returns can be interpreted as a quantification of the bond's convexity, its expected sign is unclear. CollinDufresne et al (2001) report both positive and negative coefficients for this variables and its economic significance is ambiguous. The changes in the slope of the interest rate curve have negative and significant effect for the CDS, being non-significant for ASP and Bonds. The negative sign of this parameter is also in line with what we expected given our interpretation of the slope as a leading indicator for future economic growth.

The liquidity proxies, measuring how expensive it is for a market participant to trade quickly, are the changes in the CDS bid-ask spread and in the Bond bid-ask spread. ${ }^{11}$ We expect positive signs for both variables in their respective markets. However their effect in other markets besides their own is unclear. The CDS liquidity factor has positive and significant effect on credit spread returns for the CDS and Bond markets. The CDS liquidity has a negative and non-significant effect on the ASP spread returns. The implication is that increases in the trading costs in the CDS market increase the spread returns in bonds and therefore there is a spillover effect from the liquidity in the CDS market to the bond market. The Bond liquidity factor has positive effect on the credit spread returns for all markets. This effect is significant for ASPs and Bonds but non-significant for CDSs. Therefore, increases in trading costs increase credit spread returns in the respective markets but there is not a spillover effect from the bond market to the CDS market. The changes in the global liquidity proxy have the expected positive sign but it is only significant in the case of CDS market. As a robustness test we employ the following firm-specific and market-wide liquidity measures. Instead of the CDS bid-ask spread we use a dummy variable which equals one if there is a trade through the GFI trading platform in a given date and zero otherwise. For the bond we employ the logarithm of the total amount issued. We re-estimate the effect of the credit spreads determinants using the new firm-specific

\footnotetext{
${ }^{11}$ Our market-based measures of liquidity can be complemented with other internal liquidity measures as suggested by Chen, Liao and Tsai (2010).
} 
liquidity proxies and find that these liquidity proxies are not significant and the R-squares remain unchanged. $^{12}$

Finally, in the case of the inertial component, our first observation is that the lagged credit spread returns present aggregate negative and significant effects which suggest the existence of a price adjustment process in the three markets being the process particularly strong in the ASP and bond markets. This remarkable result is worth noting because for ASP and Bonds, their own lagged dependent variables are by far the most significant explanatory factor. In fact, the first order autocorrelation of the series amounts to $32 \%$ and $34 \%$ for ASP and Bonds respectively, both with a pvalue very close to 0 . A persistent autocorrelation raises the question of inefficiencies in both the ASP and Bond markets. Recent research (Bystrom, 2006) however shows that in the iTraxx market, which presents similar first-order autocorrelation levels, it is not possible to exploit the autocorrelation with simple trading strategies when taking transaction costs into account. ${ }^{13}$ It is also worth mentioning that the lagged stock return effect is particularly strong for CDS which suggests that stock returns are powerful leading indicators of CDS returns as previously documented by Norden and Weber (2009) and Forte and Peña (2009).

To judge the overall fit of our set of proxies for expected loss, risk premium, liquidity premium, and inertial component the $\mathrm{R}^{2} \mathrm{~S}$ are of particular interest. The $\mathrm{R}^{2}$ are $11.6 \%$ (CDS), $12.1 \%$ (ASP), and $14.1 \%$ (Bond) and indicate that our explanatory variables have some information content. However, the unexplained fraction of the variability of the credit returns is sizeable. This result is remarkable given the comprehensive set of explanatory variables employed. We would expect the residuals to show a weak contemporaneous correlation, because the common factors are accounted for by the explanatory variables. Nevertheless, the average correlation among the residuals in the CDS, ASP and Bond equations are $0.50,0.40$ and 0.40 , respectively. This interdependence in the residuals indicates

\footnotetext{
${ }^{12}$ There are other candidates as bond liquidity proxies such as the bond age or the time to maturity. Due to the nature of these variables, we should employ the value at a given time-point and not the dynamic values. These dynamic values reflect mainly time effects rather than liquidity effects and so we employ the age and time to maturity at a given point of time to. We use these alternatives as bond liquidity proxies and find that they are not significant and the R-squares remain unchanged.

${ }^{13}$ A detailed analysis of possible arbitrage strategies is beyond the scope of this paper and is left for future research.
} 
the presence of unobserved common components, which are not reproduced by our models. Principal component analysis reveals that for bonds, ASP and CDS innovations, the first principal component explains $20 \%, 20 \%$ and $32.5 \%$ of total residual variance, respectively. This points out to a possibly influential latent variable albeit not as influential as the one found in Collin-Dufresne et al (2001) where a single strong latent factor captured $75 \%$ of the residual variation of credit spread changes. Ten principal components are needed to explain $54 \%, 54 \%$ and $64 \%$, respectively. ${ }^{14}$ The implication is that bond, ASP and CDS innovations are driven by some factors unrelated to firm-specific fundamentals (stock returns and lagged credit spreads) and to overall financial variables (interest rates), risk premium, and liquidity premium. Furthermore, the correlation between the CDS's residuals and ASP's residuals is 0.01, between CDS's residuals and Bonds' residuals is 0.01 and between ASP's residuals and Bonds' residuals is 0.65 . This interesting result suggests that CDS innovations are unrelated to the innovations in the other two markets which in, on the contrary, are closely related.

We next break down the contributions of the expected loss, liquidity premium, risk premium, and inertial factor components obtained in the estimations of equation (5). Results are shown in Figure 1 and in the associated Table 2. The CDS market is more influenced by risk premium variables than the other two markets. Actually, the risk premium factor explains the largest share in the CDS spread returns $(64.7 \%)$ but only explains a minimal fraction of ASP and Bond credit spreads. The expected loss component is negligible in the ASP and bond markets with shares close to $0 \%$ but is the second most important factor in the CDS market with a share of $23.4 \%$. The liquidity premium is very low for CDS (its share is equal to 2.7\%) but is noticeably higher for ASP and Bonds (their shares are equal to $16.2 \%$ and $21 \%$, respectively). The inertial component explains the largest share in the ASP and Bond spread returns with proportions of $81 \%$ and $77 \%$ respectively but it is of minor importance for CDS. These differences in the relative weight of the different spread return components may be one possible

\footnotetext{
${ }^{14}$ As we have missing values, we impute the missing values of the dataset with a Principal Components Analysis (PCA) model as a preliminary step before performing a PCA on an incomplete dataset. The imputation is done by means of an iterative PCA algorithm. This algorithm first imputes the missing values with initial values (the means of each variable), then performs PCA on the completed dataset, imputes the missing values with the reconstruction formulae of a given order and iterates until convergence (see Josse and Husson (2010) for further details). The standard PCA methodology uses the common observations to all the firms and given that we have an unbalanced panel, with missing observations at the beginning and the end of the sample, it would limit our analysis to the use of 270 observations.
} 
explanation of the decoupling episodes reported by market observers. For instance, if the risk premium or expected loss factors increase strongly their effects will be more apparent in the CDS market than in the Bond or ASP markets, inducing a divergence between the spreads in the different markets.

The shares of the four determinants of the credit spread returns need not to be constant over time. We compute the dynamic contributions by means of a rolling windows panel regression of equation (5). The series of the dynamic $\mathrm{R}^{2} \mathrm{~s}$ are shown in Panels A, B and C of Figure 2. Panel A of Figure 2 presents the CDS spread changes $\mathrm{R}^{2}$ series. The contribution of liquidity to the $\mathrm{R}^{2}$ remains low and stable during the whole sample period. However, the contributions of the other three factors present a significant variation over time, increasing for the risk premium and the expected loss components and decreasing for the inertial component. Interestingly, we find that before the crisis the behavior of the CDS market was relatively similar to the other two markets in the sense that the inertial component was, by far, the most significant factor. However, after the summer of 2007 the CDS market becomes much more sensitive to the risk premium factor whereas the inertial factor losses influence. The steady increase of the expected loss factor after the start of the subprime crisis is also worth noting.

The strong dominant component in the bond and ASP markets is the inertial component followed by the liquidity premium. The risk premium and the expected loss components are not particularly relevant. The overall impression is that, especially during the crisis the CDS spread changes are dependent to some extent on systematic risk factors while the ASP and bond spread changes are primarily determined by inertial factors possibly associated with market frictions. Although the trends in Panels B and C are similar, we may observe some differences. For instance, in summer 2009 the contribution of the risk premium (inertial component) in the ASP market is close to $15 \%$ (60\%) while in the bond market is around 5\% (70\%). Thus, although ASP spreads are directly connected to bond spreads (the bond is part of the ASP) the effect of the potential credit spreads' determinants differs between both spreads.

\subsection{Credit Spreads Co-Movements}


The previous sub-section documents the limited usefulness of the structural models related variables; the common risk factors; the liquidity measures; and the inertial components in explaining corporate credit spreads returns. In this section we employ the filtered returns to study the behavior of the unexplained proportion of credit spread changes and the potential co-movements derived from this unexplained component which accounts for a high proportion of the variability in the changes of credit spread returns. Figure 3 reports the 30-day moving average of the average intra-market DCCs over time for CDS, ASP and bond innovations. DCCs reported in Figure 3 are obtained after averaging, over the 50 firms, the DCCs between the innovations of a given firm $i$ and the innovations of an equally-weighted market portfolio which is constructed with the remaining 49 firms (excluding the firm being assessed in bivariate estimations). The average DCCs in CDS innovations before the crisis are lower than after (0.43 vs. 0.47$)$ being the opposite for ASPs (0.41 vs. 0.33$)$ and Bonds (0.44 vs. 0.34). Thus, internal dependence increases slightly for CDSs but decreases for ASP and Bonds. Using a test of differences between the means before and during the crisis, we find that the average DCCs are significantly higher during than before the crisis in the CDS market but they are significantly lower during the crisis in the ASP and bond markets. In the pre-crisis period, intra-market dependence was similar among the three credit markets being slightly lower in the ASP market. However, during the crisis, intra-market dependence increases in the CDS market (9\% increase) but decreased substantially (close to 20\% decrease) in the ASP and Bond markets. ${ }^{15,16}$ One reason justifying the decrease in intramarket ASP and bond markets co-movements in the crisis period is the concentration of some players in credit markets abandoning these markets. This "extinction" of a portion of individuals operating in various markets together with the heterogeneity and the disperse distribution of the remaining market players in ASP and Bond markets, could be the causes behind the trend towards lower intra-market dependence observed in these markets. Further evidence on this issue can be found in Mayordomo et

\footnotetext{
${ }^{15}$ In order to calculate the average DCCs before and during the crisis we first estimate the break-points for each series of DCCs for the CDS, ASP and bond innovations by means of the algorithm described in Bai and Perron (2003) for simultaneous estimation of multiple breakpoints. See also Zeileis, Kleiber, Krämer, and Hornik (2003). We find that the breakpoint for the DCCs series of CDSs (ASPs and Bonds) is 25th July 2007 (12th June 2007 and 13th July 2007, respectively). We consider the dates after the minimum of the three previous dates (12th June 2007) as the crisis period and split the sample period in two subsamples at this point.

${ }^{16}$ The individual DCCs for these three combinations of innovations are available upon request. We also calculate the average pairwise correlations between credit spreads and find a similar behavior as in the DCC correlations between innovations. The average correlation between CDS spreads before the crisis are lower than after $(0.47$ vs. 0.84$)$ and the opposite is true for ASP spreads ( 0.53 vs. 0.48$)$ and Bond spreads (0.52 vs. 0.47$)$.
} 
al. (2011). We repeat the DCC estimation using the innovations of an individual firm $i$ and the innovations of a value-weighted market portfolio in which the weights are proportional to the firm market capitalization. The new average DCCs over the 50 firms do not show significant differences with respect to the ones shown in Figures 3 and are available upon request.

Figure 4 reports the 30-day moving average of the average inter-market DCCs over time for CDSASP, CDS-Bond, and ASP-Bond innovations. DCCs reported in Figure 4 are obtained after averaging, over the 50 firms, the DCCs between the innovations of a given credit spread for firm $\mathrm{i}$ and the innovations of a different credit spread for the same firm $i$ (same firm and different credit spread returns innovations). In the pre-crisis period, the inter-market dependence between ASP and Bonds, measured by the average DCC, is high (average 0.65) and remains stable during the crisis (average 0.66). ${ }^{17}$ One can observe from Figure 4 and also from Table 1 how closely the bond and ASP spreads follow each other and also that their dependence has remained relatively stable throughout the crisis. Therefore it seems that the cash component in the ASP contract is the dominant one because the close association between the ASP innovations and the pure cash (bond) contract innovations'. However, the DCC between bond and ASP is far away from one in spite of the fact the ASP arrangement involves first the acquisition of a (corporate) bond position and then an interest rate swap with the seller in order to transfer the fixed coupon payments into a floating one, suggesting that the derivative component (related to the IRS) has some impact too. The inter-market dependence of CDS and ASP (Bonds) presents also a stable behavior. The pre-crisis average DCCs in ASP-CDS innovations are very low and identical to the during crisis average DCCs $(0.02$ vs. 0.02). Thus, given that no significant correlation is found, the interpretation is that the derivatives element in the ASP contract (IRS) is essentially unrelated with the innovations in the pure credit derivative contract (CDS) . The same behavior is observed for the average DCCs in Bond-CDS innovations (0.02 vs. 0.01) ${ }^{18}$ The

\footnotetext{
17 The average correlation between ASP and Bond spreads during the crisis is slightly higher than before the crisis (0.98 vs. 0.97).

18 The individual DCCs for these two combinations of innovations are available upon request. The average correlations between credit spreads are also calculated and re.ect the same behavior as the DCCs between innovations. The average correlation between ASP and CDS spreads before the crisis are higher than after it (0.92vs. 0.96) and the same is true for the correlations between Bond and CDS spreads (0.91 vs. 0.96).
} 
overall impression is that once we control by the effect of the expected loss, risk premium, and liquidity premium terms there are not noticeably differences in the degree of inter-market dependence. ASP and Bond markets innovations remain dependent whereas CDS innovations are unrelated to ASP and Bond innovations.

Counterparty risk could be another potential driver of the CDS credit spreads in addition to the four terms in which the spreads are broken down. We proxy counterparty risk by means of the first principal component (PC) obtained from the CDS spreads of the main 12 banks which act as dealers in this market, namely: Bank of America, Citigroup, Deutsche Bank, Credit Suisse, Goldman Sachs, Barclays, HSBC, JP Morgan, Morgan Stanley, Societé Generale, UBS, and Wachovia. The first principal component series should reflect the common default probability that can be thought of an aggregate measure of counterparty risk. Actually, the first PC for the series of CDS spreads of the previous dealers explains $87.5 \%$ of the total variance. We isolate the effect of global variables (implicit in this measure of counterparty risk factor) by regressing such factor on the global variables (changes in EONIA interest rate, VDAX Index, LIBOR-OIS, 10-year interest rate, volatility of 10year interest rate, slope, and global liquidity; S\&P 500 returns, and S\&P 500 squared returns) and using the residual as the counterparty risk which is not explained by the global factors. The average differences between the intra-market and inter-market DCCs obtained from the base-case innovations $e(j, i, t)$ and the new innovations obtained using the counterparty risk factor are close to zero. The average differences in the intra-market DCCs are 0.029, -0.001 and 0.000 for the CDS, ASP, and Bond markets, respectively. The average differences in the inter-market DCCs are $-0.006,-0.003$ and -0.003 for the ASP-CDS, Bond-CDS, and ASP-Bond markets, respectively. The results suggest that the inclusion of counterparty risk, as measured by the variable we employ here, does not affect materially our conclusions.

\section{Conclusions}

This paper investigates the dynamic dependences of the credit spread returns for fifty European firms using their CDS, ASP, and bond's prices from 2005 to 2009. We show that credit spread returns are 
largely driven by innovations both in the case of the cash and the derivatives credit risk markets. Regarding the proportion of the variation in credit spread returns which is actually explained by the explanatory variables, the CDS return is more influenced by risk premium-related and expected loss factors than the other two returns. Bond and ASP daily returns are mostly unrelated with standard explanatory variables and driven by inertial factors. The impact of each factor changes over time.

Intra-market dependence during the current crisis decreases for bonds and ASP innovations. The intermarket dependence is high and stable over time between bonds and ASP innovations whereas CDS innovations are largely unrelated to both bonds and ASP innovations. The implication of the former is that ASP and bonds innovations are, on average, closely related. The implication of the later is possibly the most salient result in our paper because the CDSs' innovations, that is, the innovations in the pure derivatives markets, are specific to this market and unrelated to the innovations in the other two credit markets. Also and given that no significant correlation is found between ASP and CDS, the interpretation is that the derivatives element in the ASP contract (IRS) is essentially unrelated with the innovations in the pure credit derivative contract (CDS). Looking forward, the implications of our results on the degree of diversification that cash and derivatives instruments provide to investors in credit risk sensitive portfolios is an interesting future research question. Additionally, another avenue for further research is the implications of these results in terms of the relative reliability of each market's price signals.

\section{Acknowledgements}

The authors thank Óscar Arce, Antonio Díaz, Javier Gil-Bazo, Neil Kellard, María RodríguezMoreno, Jesús Saurina, Javier Suárez, and seminar participants at the XVIII Finance Forum, the Emerging Scholars in Banking and Finance Conference at Cass Business School, and the 29th SUERF Colloquium for all their comments and suggestions. The authors acknowledge financial support from MCI grant ECO2009-12551. The usual disclaimer applies. 


\section{References}

Acharya, V., and Johnson, T. (2007), "Insider trading in credit derivatives", Journal of Financial Economics, 84, 110-141.

Acharya, V., S. Schaefer, S. and Zhang, Y. (2007) "Liquidity risk and correlation risk: A clinical study of the General Motors and Ford Downgrade of May 2005", Working Paper, SSRN.

Alexopoulou, I., Andersson, M., and Georgescu, O. A. (2009) “An Empirical Study of the Decoupling Movements between Corporate Bonds and CDS Spreads" European Central Bank, Working Paper 1085.

Amato, J. (2005) "Risk Aversion and Risk Premia in the CDS Market". BIS Quarterly Review, December, 55-68.

Anderson, M. (2010) "Contagion and Excess Correlation in Credit Default Swaps". Fisher College of Business, Ohio State University. Working Paper.

Annaert, J., De Ceuster, M., Van Roy, P., and Vespro, C. (2010) "What Determines Euro Area Bank CDS Spreads?” National Bank of Belgium Working Paper No. 190.

Arora, N., Gandhi, P., and Longstaff, F. (2009), "Counterparty Credit Risk and the Credit Default Swap Market" Working Paper, UCLA.

Bai J., and Perron P. (2003), "Computation and Analysis of Multiple Structural Change Models", Journal of Applied Econometrics, 18, 1-22.

Bystrom, H.N.E. (2006), "Credit Grades and the iTraxx CDS Index Market", Financial Analysts Journal 62(6), 65-76.

Blanco, R., Brennan, S., Marsh, I. W., (2005) “An Empircal Analysis of the Dynamic Relationship between Investment Grade Bonds and Credit Default Swaps", Journal of Finance 60, 2255-2281.

Boss, M. and M. Scheicher (2002) "The Determinants of Credit Spread Changes in the Euro Area" BIS Paper n. 12.

British Bankers Association (BBA). BBA Credit Derivatives Report 2001/2002. London: BBA Enterprises Ltd, 2002.

Cappiello, L., Engle, R. F., and Sheppard, K. (2006) "Asymmetric Dynamics in the Correlations of Global Equity and Bond Returns”. Journal of Financial Econometrics, Vol. 4, No. 4, pp. 537-572.

Chen, L., Lesmond, D.A. and Wei, J. (2007) "Corporate Yield Spreads and Bond Liquidity", Journal of Finance, 62, 119-149.

Chen, T-K, Liao, H-H., and Tsai, P-L (2010) "Internal Liquidity Risk in Corporate Bond Yield Spreads" Journal of Banking and Finance, 35, 978-987.

Collin-Dufresne, P., Goldstein, R., and Martin, J.S. (2001) "The Determinants of Credit Spread Changes". Journal of Finance, 56, 1926-1957. 
Coudert, V. and Gex, M. (2008) "Co-movements in the CDS Market and Relationship to other Financial Markets: the Case of the GM and Ford Crisis in 2005”, Working Paper.

Delianedis, G. and Geske, R. (2001) "The Components of Corporate Credit Spreads: Default, Recovery, Tax, Jumps, Liquidity, and Market Factors", University of California, Working Paper.

Elton, E. J., Gruber, M. J., and Agrawal, D. (2001) "Explaining the Rate Spread on Corporate Bonds”. Journal of Finance 56, 247-278.

Engle, R. (2002) "Dynamic conditional correlation: A simple class of multivariate generalized autoregressive conditional heteroskedasticity models", Journal of Business and Economics Statistics, no. 3, p. 339-350.

Engle R. F. and Sheppard, K. (2001) "Theoretical and empirical properties of dynamic conditional correlation multivariate GARCH”, Working Paper 8554, NBER, 2001.

Ericsson, J., Jacobs, K. and Oviedo-Helfenberger (2009) "The Determinants of Credit Default Swap Premia", Journal of Financial and Quantitative Analysis, 44, 109-132.

European Central Bank (2009) Credit Default Swaps and Counterparty Risk, August 2009.

Forte, S. and Peña, J.I. (2009) "Credit Spreads: Theory and Evidence About The Information Content of Stocks, Bonds and CDSs", Journal of Banking and Finance, 33, 2013-2025.

Francis, C., Kakodkar, A., Martin, B., 2003. Credit Derivative Handbook 2003. A Guide to Products, Valuation, Strategies and Risks. Merrill Lynch Global Securities Research and Economics Group, April.

Houweling, P., Mentink, A. and Vorst, T. (2005) "Comparing Possible Proxies of Corporate Bond Liquidity”, Journal of Banking and Finance, 29, 1331-1358.

Josse, J., and Husson, F. (2010) Multiple Imputation in PCA.

Kim, S. J., Lucey, B. M., and Wu, E. (2005) "Dynamics of Bond Market Integration between Established and New European Union Countries”. Journal of International Financial Markets, Institutions and Money, Vol. 16, No. 1, pp.41-46.

Kwan, S. H. (1996) "Firm-Specific Information and the Correlation between Individual Stocks and Bonds", Journal of Financial Economics Vol. 40, pp. 63-80.

Levin, A., Perli, R., Zakrajëk, E., (2005) "The Determinants of Market Frictions in the Corporate Market" Computing in Economics and Finance 2005, 379, Society for Computational Economics. Li, X.M., and Zou, L.P. (2008) "How do Policy and Information Shocks Impact Comovements of China's T-Bond and Stock Markets?", Journal of Banking and Finance Vol. 32, pp. 347-359.

Longstaff, F.A., Mithal, S. and Neis, E. (2005), "Corporate Yield Spreads: Default Risk or Liquidity? New Evidence from the Credit Default Swap Market”, Journal of Finance 60, 2213-2253.

Longstaff, F. A., and Schwartz, E. S., (1995). "A Simple Approach to Valuing Risky Fixed and Floating Rate Debt”, Journal of Finance 50, 789-821. 
Mayordomo, S., Peña J. I., and Romo, J. (2011), “The Effect of Liquidity on the Price Discovery Process in Credit Derivatives Markets in Times of Financial Distress". European Journal of Finance, 17, 851-881.

Merton, R. C. (1974), "On the Pricing of Corporate Debt: The Risk Structure of Interest Rates", Journal of Finance 29, 449-470.

Norden, L., and Weber, M., (2009) "The Co-Movement of Credit Default Swap, Bond and Stock Makets: an Empirical Analysis”. European Financial Management 15, 529-562.

Perraudin, W. and Taylor, A. (2003) "Liquidity and Bond Market Spreads", Bank of England, Working Paper.

Rodriguez-Moreno, M. and Peña, J. I., (2010) "Systemic Risk Measures: The Simpler the Better?" (September 1, 2010). Available at SSRN: http://ssrn.com/abstract=1681087

Savva C.S., Osborn D.R., and Gill L. (2009). "Spillovers and correlations between U.S. and major European stock markets: The role of the Euro", Applied Financial Economics, 19, 1595-1604.

Stulz, R. (2009) "Credit Default Swaps and the Credit Crisis". ECGI Finance Working Paper $264 / 2009$.

Tang, D.Y. and Yan, H. (2007) "Liquidity and Credit Default Swap Spreads”, Working Paper.

Zeileis A., Kleiber C., Krämer W., Hornik K. (2003), “Testing and Dating of Structural Changes in Practice", Computational Statistics and Data Analysis, 44, 109-123.

Zhu, H., (2006) "An Empirical Comparison of Credit Spreads between the Bond Market and the Credit Default Swap Market”. Journal of Financial Services Research 29, 211-235. 
Table 1: Descriptive statistics

This table reports descriptive statistics (in basis points) for the CDS spread, the ASP spread, and the bond spread,respectively.

\begin{tabular}{|c|c|c|c|c|c|c|c|c|c|c|c|c|}
\hline & \multicolumn{4}{|c|}{ CDS Premium (basis points) } & \multicolumn{4}{|c|}{ Asset Swap Spread (b.p.) } & \multicolumn{4}{|c|}{ Bond Spread (b.p.) } \\
\hline Issuer & Mean & Min & Max & SD & Mean & Min & Max & SD & Mean & Min & $\operatorname{Max}$ & SD \\
\hline$\overline{\text { Akzo I }}$ & 48.20 & 13.58 & 172.60 & 38.36 & 49.07 & 0.70 & 254.30 & 60.10 & 50.47 & 0.30 & 304.70 & 61.97 \\
\hline Akzo II & 17.50 & 6.35 & 50.05 & 10.56 & 15.50 & 1.20 & 49.40 & 10.88 & 15.10 & 0.50 & & 11.02 \\
\hline BMW & 82.76 & 6.61 & 537.50 & 121.96 & 56.70 & 1.10 & 479.00 & 85.99 & 8.63 & 1.40 & 515.40 & 88.24 \\
\hline Bouygues I & 53.87 & 12.00 & 270.32 & 55.10 & 55.59 & 9.40 & 262.10 & 52.31 & 55.74 & 11.80 & 263.50 & 50.78 \\
\hline Bouygues II & 30.86 & 11.92 & 119.90 & 19.78 & 20.75 & 0.56 & 94.90 & 11.65 & 20.35 & 0.70 & 94.00 & 10.94 \\
\hline British AM Tob. I & 22.90 & 6.04 & 54.00 & 13.18 & 23.10 & 0.25 & 76.13 & 11.86 & 23.57 & 0.20 & 77.00 & 11.96 \\
\hline British AM T & 42.75 & 13.12 & 136.64 & 26.46 & 71.25 & 16.90 & 293.10 & 54.39 & 73.51 & 20.00 & 298.20 & 54.85 \\
\hline Carrefour I & 33.69 & 9.43 & 153.67 & 25.33 & 35.62 & 2.80 & 174.60 & 34.00 & 35.09 & 0.30 & 174.20 & 32.37 \\
\hline arrefour II & 28.31 & 6.80 & 159.47 & 26.16 & 18.93 & 0.20 & 116.30 & 17.39 & 18.78 & 0.40 & 137.40 & 20.50 \\
\hline Casino I & 96.30 & 31.03 & 390.00 & 68.26 & 115.75 & 33.70 & 389.70 & 84.81 & 119.48 & 36.90 & 418.30 & 87.37 \\
\hline sino II & 81.09 & 22.31 & 390.00 & 66.33 & 77.63 & 15.72 & 284.90 & 50.72 & 4.41 & 16.70 & 365.90 & 65.72 \\
\hline Compass Gr & 27.08 & 9.44 & 83.29 & 15.89 & 32.61 & 0.70 & 104.50 & 18.30 & 32.25 & 0.20 & 103.60 & 18.31 \\
\hline Edison Spa & 45.01 & 6.51 & 198.00 & 47.33 & 57.93 & 4.70 & & 56.17 & 7.45 & 3.20 & & 53.99 \\
\hline Enel & 77.08 & 7.97 & 743.31 & 116.46 & 28.09 & 1.00 & 146.00 & 28.87 & 28.77 & 1.30 & 150.10 & 28.69 \\
\hline Energia & 31.98 & 5.27 & 150.52 & 29.34 & 25.62 & 2.53 & 165 & 30.53 & 05 & 0.70 & 90 & 63.47 \\
\hline Energia & 38.42 & 6.81 & 154.27 & 32.85 & 50.04 & 0.32 & & 53.29 & & 0.80 & 70 & 52.50 \\
\hline E.ON & 18.29 & 4.98 & 68.90 & 13.66 & 14.91 & 0.30 & 54.77 & 10.28 & 14.71 & 0.60 & 10 & 8.90 \\
\hline France & 29.42 & 7.64 & 0 & 18.17 & 79 & 0.81 & & 13.96 & & 1.60 & & 12.28 \\
\hline $\mathrm{Ib}$ & 49.86 & 6.82 & 295.50 & 50.31 & 40.58 & 0.91 & 211.00 & 43.82 & 40.88 & 0.80 & 218.30 & 42.50 \\
\hline Ibe & 24.83 & 5.99 & 106.92 & 21.15 & 9.86 & 0.50 & 37.09 & 9.06 & 9.67 & 0.60 & 0 & 9.60 \\
\hline & 105.17 & 31.545 & 438.26 & 93.67 & 116.50 & 29.10 & 377.00 & 107.39 & 23.55 & 1.70 & & 115.72 \\
\hline Kon & 62.60 & 25.16 & 159.51 & 25.90 & 89.29 & 29.50 & 321.60 & 51.76 & 93.17 & 33.30 & & 54.87 \\
\hline & & 9.09 & & 45.30 & & & & & & & & 9 \\
\hline Lo & 41.49 & 5.86 & 246.00 & 44.03 & 41.20 & 1.74 & 23 & 39.39 & 41.20 & 1.20 & & 38.45 \\
\hline PPR & 145.24 & 24.73 & 759.03 & 170.27 & 123.15 & 34.77 & 553.70 & 122.38 & 126.64 & 36.10 & 60 & 127.72 \\
\hline & 36.19 & 5.05 & 149.96 & 35.18 & 27.81 & 5.00 & 73.80 & 13.10 & 27.22 & 3.30 & & 12.27 \\
\hline & 64.94 & 9.69 & 441.16 & 88.03 & 64.26 & 8.37 & 368.40 & 70.68 & 64.24 & 9.20 & 90 & 71.05 \\
\hline & & & 35.72 & & & & & 10. & & & & 0 \\
\hline & 02 & 10.13 & 4.47 & 39.62 & 77 & 0.33 & & 13 & 96 & 0.70 & & 12.65 \\
\hline & 101.25 & 15.93 & 435.63 & 99.98 & 102.35 & 16.90 & 458.10 & 102.30 & 105.96 & 19.90 & 70 & 105.57 \\
\hline & 83.40 & 11.65 & 412.04 & 92.52 & 68.61 & 9.60 & 323.10 & 65.04 & 72.34 & 11.80 & 30 & 74.08 \\
\hline & 37.83 & 10.24 & 119.40 & 21.89 & 37.27 & 8.60 & & & & 10.20 & & 19.35 \\
\hline & 42.47 & 9.34 & 238.85 & 45.20 & 33.89 & 1.66 & 175.60 & & & 1.40 & & 36.05 \\
\hline & 14.46 & 4.32 & 41.93 & 9.73 & 26.92 & 3.39 & & 13 & & 0.20 & & 13.25 \\
\hline & 85.45 & 20.37 & 339.33 & 87.65 & 09 & 21.30 & 276.70 & 58.45 & 83.30 & 24.60 & 00 & 61.65 \\
\hline ip & 50.19 & 14.80 & 302.73 & 54.83 & 86 & 18.80 & 303.50 & 58.64 & 57 & 8.50 & 90 & 61.93 \\
\hline & 4.16 & 23.01 & 546.17 & 107.89 & 96.89 & 20.90 & 434.70 & 80.01 & 103.29 & 24.00 & 50 & 93.85 \\
\hline & 110.51 & 24.40 & 540.33 & 109.71 & 125.83 & 22.00 & 536.70 & 125.07 & 124.85 & 23.70 & 30 & 125.75 \\
\hline $\mathrm{Te}$ & 61.87 & 16.46 & 247.69 & 45.91 & 65.04 & 17.70 & 276.10 & 45.76 & 67.52 & 20.20 & .00 & 45.64 \\
\hline & & 9.55 & 142.58 & 25.55 & 51.84 & 3.75 & 326.80 & 47.79 & 55.05 & 5.50 & 321.90 & 50.02 \\
\hline $\mathrm{Te}$ & 29.78 & 4.06 & 182.00 & 39.73 & 32.07 & 1.50 & 246.30 & 44.88 & 23.28 & 0.80 & 70 & 38.46 \\
\hline & 33.88 & 5.00 & 182.19 & 39.95 & 37.01 & 0.63 & 189.70 & 42.07 & 37.50 & 0.50 & 197.40 & 41.20 \\
\hline & 46.22 & 9.27 & 300.99 & 50.99 & 47.27 & 0.70 & 211.10 & 52.45 & 49.32 & 3.70 & .20 & 59.45 \\
\hline & 124.85 & 17.12 & 540.00 & 143.60 & 83.96 & 0.20 & 313.30 & 84.83 & 88.39 & 0.10 & 548.90 & 91.76 \\
\hline & 42.22 & 7.29 & 382.50 & 51.45 & 50.41 & 6.30 & 215.80 & 50.53 & 50.21 & 5.60 & .30 & 48.52 \\
\hline Vinci & 35.75 & 12.26 & 124.42 & 25.39 & 30.55 & 4.78 & 107.00 & 15.62 & 30.26 & 2.90 & 104.70 & 14.92 \\
\hline & 45.52 & 15.74 & 113.02 & 22.94 & 57.32 & 20.14 & 138.72 & 31.10 & 59.65 & 22.50 & 130.30 & 31.67 \\
\hline & 25.89 & 10.90 & 68.50 & 15.18 & 18.56 & 0.40 & 56.84 & 11.05 & 18.73 & 0.10 & & 10.35 \\
\hline Volkswagen & 84.92 & 10.82 & 360.02 & 86.81 & 77.40 & 6.98 & 352.20 & 84.61 & 80.00 & 7.50 & 363.40 & 86.46 \\
\hline & 103.02 & 9.73 & 733.80 & 177.25 & 116.60 & 0.20 & 777.80 & 205.26 & 121.24 & 0.30 & 857.90 & 218.46 \\
\hline Average & 54.93 & 11.86 & 266.76 & 54.37 & 53.90 & 8.01 & 237.20 & 49.69 & 55.37 & 8.62 & 269.45 & 51.98 \\
\hline
\end{tabular}


Table 2: Determinants of the credit spread changes

This table reports the results obtained when we estimate the effect of the determinants of the credit spread returns using equation (6). The first column presents the regression results for the CDS returns while the second and third columns reports the results when the dependent variables are the ASP and the Bond returns, respectively. The sample is formed by 50 reference entities and spans from November 2005 to June 2009. We fit an unbalanced panel model using Ordinary Least Squares (OLS) regression robust to heteroskedasticity and cross-sectional correlation across firms for each market (CDS, ASP, and Bond markets). We calculate the aggregated effects (agg. eff.) for all variables with lagged terms by means of the sum of the lagged coefficients related to such variable and the p-value whose null hypothesis is that the sum of all the lagged coefficients is zero. The symbol ${ }^{* * * *}\left({ }^{* *}\right.$ and $\left.{ }^{*}\right)$ denotes statistical significance at the $1 \%$ (5\% and $10 \%$, respectively) level.

\begin{tabular}{|c|c|c|c|c|c|c|}
\hline & \multicolumn{2}{|c|}{ CDS } & \multicolumn{2}{|c|}{ ASP } & \multicolumn{2}{|c|}{ Bond } \\
\hline & coeff. & agg. eff. & coeff. & agg. eff. & coeff. & agg. eff. \\
\hline Stock returns & $-0.251 * * *$ & & $-0.091 *$ & & $0.144 *$ & \\
\hline Stock returns/credit spread & $2.238 * * *$ & & $1.181 * *$ & & 0.122 & \\
\hline Squared stock returns & $0.327 * * *$ & & -0.013 & & -0.144 & \\
\hline Changes in EONIA interest rate & $-0.023 * *$ & & -0.003 & & -0.024 & \\
\hline Changes in VDAX Index & $0.166^{* * *}$ & & -0.033 & & -0.018 & \\
\hline S\&P 500 returns & $-0.160 * * *$ & & 0.062 & & $-0.515 * * *$ & \\
\hline S\&P 500 squared returns & $2.390 * * *$ & & $5.143^{* * *}$ & & $4.882^{* * *}$ & \\
\hline Changes in Libor-OIS & 0.0001 & & $0.023^{* * *}$ & & $0.029 * * *$ & \\
\hline Changes in ten-year interest rate & $-0.809 * * *$ & & $-0.827 * * *$ & & -0.153 & \\
\hline Changes in the volatility of ten-year interest rate & 0.013 & & $0.071 * *$ & & 0.022 & \\
\hline Changes in the slope (10year - 3month rates) & $-0.016 * * *$ & & 0.004 & & -0.005 & \\
\hline Changes in bond liquidity (bid-ask) & 0.001 & & $0.073 * * *$ & & $0.098^{* * *}$ & \\
\hline Changes in CDS liquidity (bid-ask) & $0.006 * * *$ & & -0.002 & & $0.005 * *$ & \\
\hline Changes in global liquidity & $0.007 * * *$ & & 0.002 & & 0.006 & \\
\hline Credit spread changes (lagged one period) & $-0.083 * * *$ & & $-0.320 * * *$ & & $-0.341 * * *$ & \\
\hline Credit spread changes (lagged two periods) & 0.006 & & $-0.115 * * *$ & & $-0.137 * * *$ & \\
\hline Credit spread changes (lagged three periods) & 0.003 & & $-0.073 * * *$ & & $-0.074 * * *$ & \\
\hline Credit spread changes (lagged four periods) & 0.005 & & $-0.029 * * *$ & & $-0.037 * * *$ & \\
\hline Credit spread changes (lagged five periods) & 0.002 & $-0.067 * * *$ & $0.026 * * *$ & $-0.511 * * *$ & 0.003 & $-0.586^{* * *}$ \\
\hline Stock returns (lagged one period) & $-0.185 * * *$ & & $-0.082 *$ & & 0.047 & \\
\hline Stock returns (lagged two periods) & $-0.050 * * *$ & & $-0.118 * * *$ & & -0.040 & \\
\hline Stock returns (lagged three periods) & $-0.112 * * *$ & & 0.033 & & -0.069 & \\
\hline Stock returns (lagged four periods) & $-0.066 * * *$ & & -0.036 & & $-0.146 * * *$ & \\
\hline Stock returns (lagged five periods) & $-0.096 * * *$ & $-0.509 * * *$ & -0.056 & $-0.258 * * *$ & $-0.106 * * *$ & $-0.315^{* * *}$ \\
\hline Stock returns (lagged one period)/credit spread & $-1.201 * *$ & & $1.157 * * *$ & & $-1.836 * * *$ & \\
\hline Stock returns (lagged two periods)/credit spread & $-1.213 * *$ & & $0.697 *$ & & -0.220 & \\
\hline Stock returns (lagged three periods)/credit spread & $1.057 *$ & & -0.085 & & 0.733 & \\
\hline Stock returns (lagged four periods)/credit spread & $-1.008 *$ & & $-1.547 * * *$ & & -1.119 & \\
\hline Stock returns (lagged five periods)/credit spread & $2.033^{* * * *}$ & -0.332 & -0.155 & 0.067 & -1.040 & $-3.482 * *$ \\
\hline Constant & 0.0004 & & -0.0004 & & -0.0005 & \\
\hline Number of observations & 34640 & & 34210 & & 34002 & \\
\hline Number of groups & 50 & & 50 & & 50 & \\
\hline Obs per group: minimum & 559 & & 516 & & 509 & \\
\hline average & 693 & & 684 & & 680 & \\
\hline maximum & 799 & & 798 & & 789 & \\
\hline R-squared & 0.116 & & 0.121 & & 0.141 & \\
\hline Wald chi2(33) & 4463.96 & & 2690.50 & & 3412.19 & \\
\hline Prob > chi 2 & 0 & & 0 & & 0 & \\
\hline
\end{tabular}


Figure 1: Contribution of the determinants of credit spreads to the explanation of the credit spread changes

This figure shows the contribution (in percentages) of the expected loss, liquidity premium, risk premiums, and inertial component terms to the R-squares obtained when we estimate the equation of the credit spread determinants.

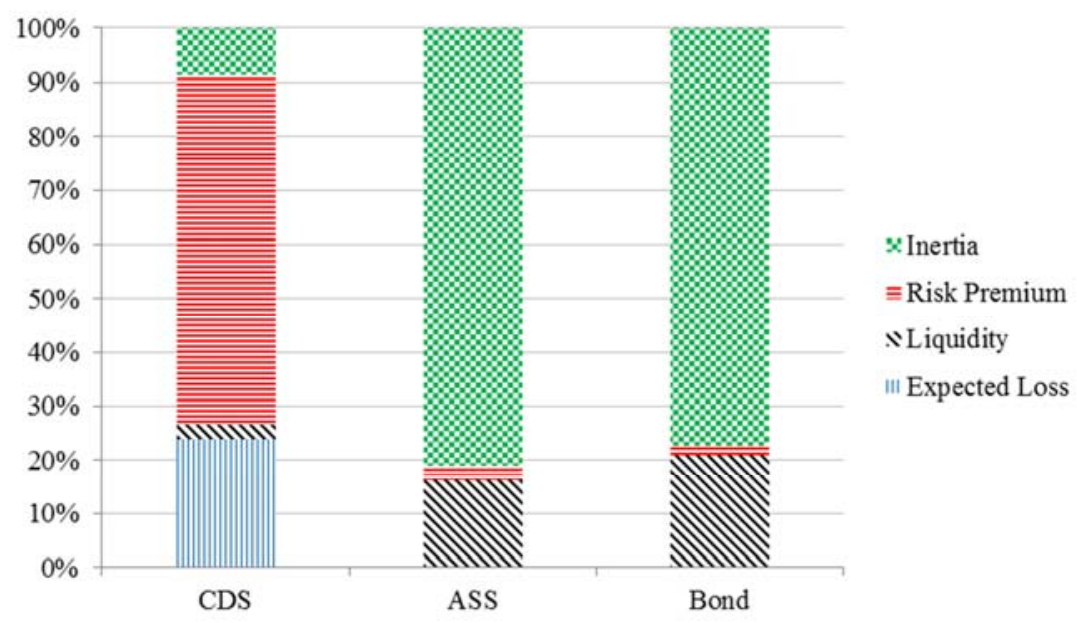


Figure 2: Dynamic Contribution of the determinants of credit spreads to the explanation of the credit spread changes

Figure 2 shows the dynamic shares of the contribution (in percentages) of the expected loss, liquidity premium, risk premiums, and inertial component terms to the R-squares obtained when we estimated the equation of the credit spread determinants. These dynamic contributions are computed by means of a rolling windows panel regression of the credit spread determinants equation. Panel A, B and C show the shares of the determinants of the CDS, ASP and bond spreads changes over time, respectively.

Panel A: CDS

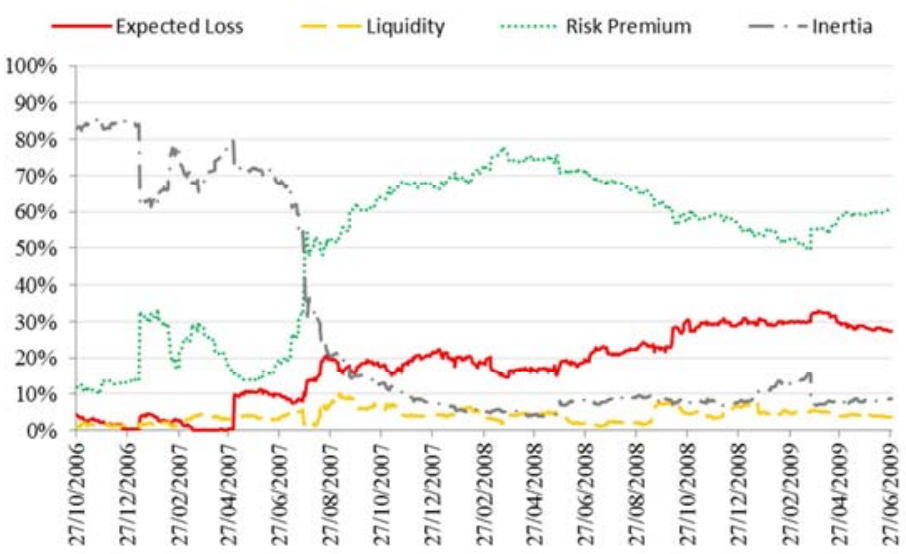

Panel B: ASP

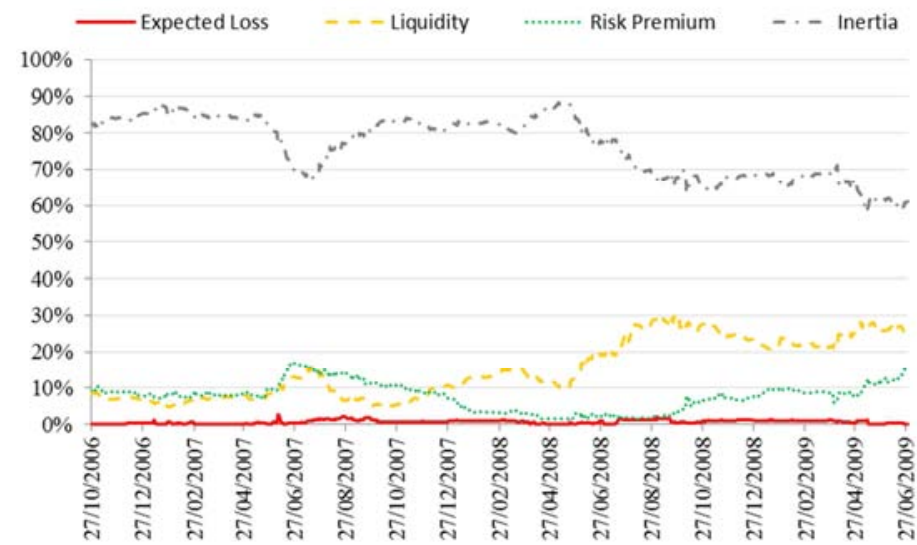

Panel C: Bond

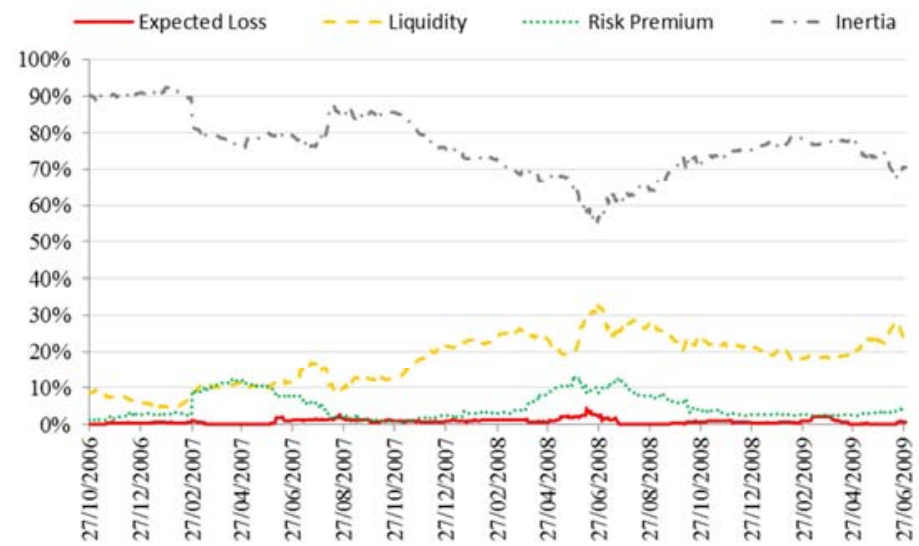




\section{Figure 3: Dynamic Conditional Correlations (DCCs) for CDS, ASP, and Bond innovations}

This figure reports the 30-day moving average of DCCs for Bond, ASP and CDS innovations which are free of the expected loss, risk premium, and liquidity terms' effects. The DCCs for the Bond (ASP and CDS) innovations are obtained by averaging over the 50 firms the DCCs obtained between each individual issuer's Bond (ASP and CDS) innovations and the overall Bond (ASP and CDS) innovations.

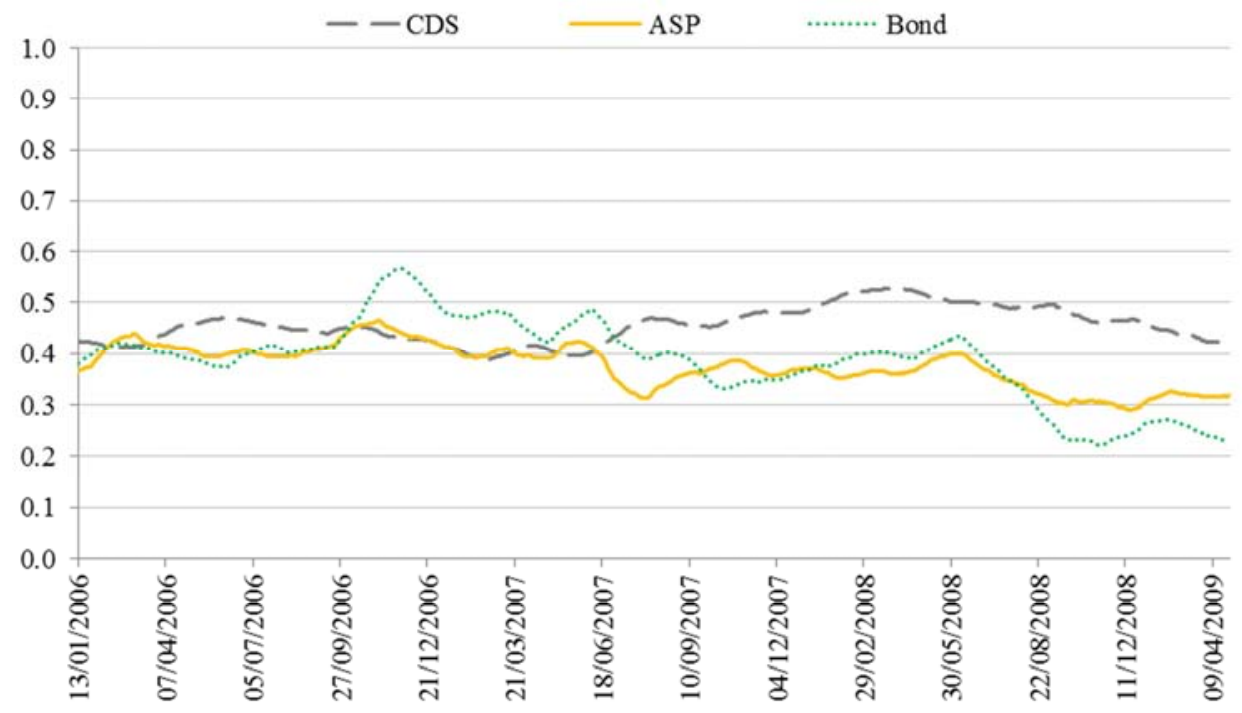

Figure 4: Dynamic Conditional Correlations (DCCs) for ASP-CDS, Bond-CDS, and ASP-Bond innovations

This figure reports the 30-day moving average of DCCs between ASP and CDS innovations, Bond and CDS innovations, and ASP and bond innovations. All these innovations are free of the expected loss, risk premium, and liquidity terms' effects. The DCCs between the ASP and CDS (between the Bond and CDS and between the ASP and Bond) innovations are obtained by averaging over the 50 issuers, the DCCs obtained between each issuer's ASP and CDS (Bond and CDS, and ASP and Bond) innovations.

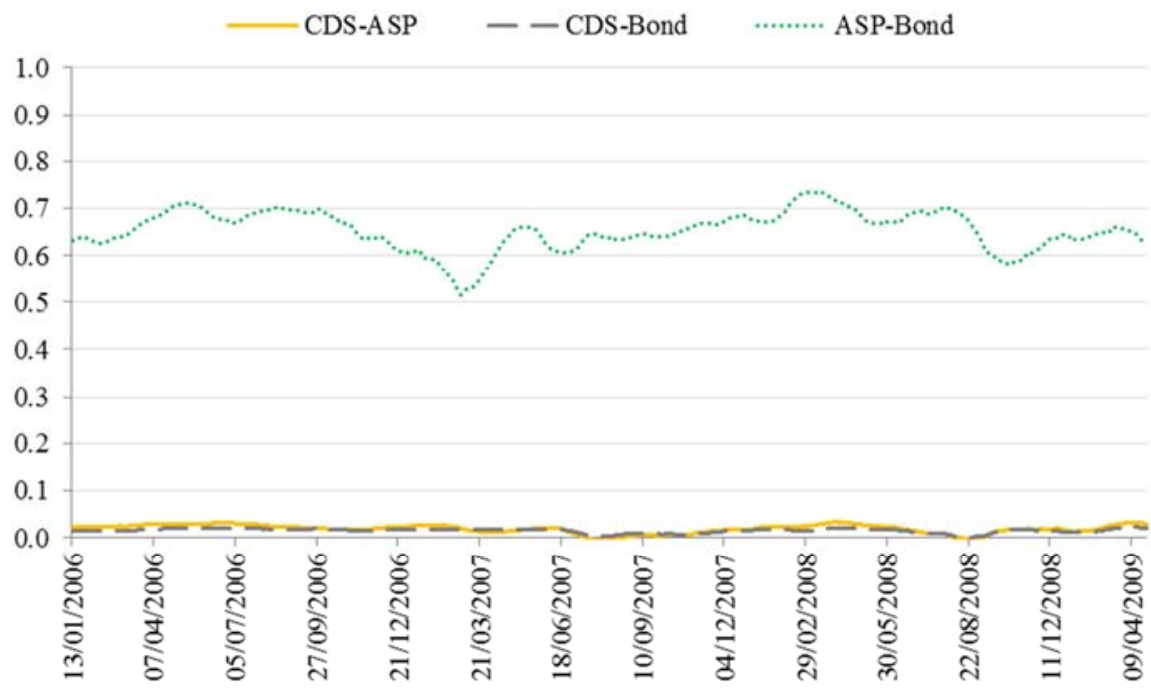

